\title{
Nuevas citas y correcciones de algas coralinas (Corallinophycidae, Rhodophyta) para el noroeste ibérico (Galicia y norte de Portugal)
}

\author{
New records and corrections of coralline algae (Corallinophycidae, Rhodophyta) \\ for the NW Iberia (Galicia and northern Portugal)
}

\author{
Juan Lugilde ${ }^{1}$, Ignacio Bárbara ${ }^{1}$, Marcos Rubal $^{2}$, Puri Veiga², Débora Borges ${ }^{3}$, \\ Isabel Sousa-Pinto ${ }^{2} \&$ Viviana Peña ${ }^{1}$ \\ ${ }^{1}$ Grupo de Biología Costera (BioCost), Facultade de Ciencias, Universidade da Coruña, \\ Campus da Zapateira, 15008. A Coruña, España. \\ ${ }^{2}$ Departamento de Biologia, Facultade de Ciências, Universidade de Porto, \\ Rua do Campo Alegre s/n 4150-181 Porto, Portugal. \\ ${ }^{3}$ CIIMAR, Centro Interdisciplinar de Investigação Marinha e Ambiental. Terminal de Cruzeiros \\ do Porto de Leixões Av. General Norton de Matos s/n 4450-208 Matosinhos, Portugal.
}

(Recibido: 30/12/2020; Aceptado: 26/03/2021)

\section{Resumen}

Las algas rojas coralinas conforman un grupo bentónico diverso en el noroeste ibérico, el cual ha sido revisitado en el contexto de una reciente tesis doctoral. En el presente trabajo, se aportan datos corológicos para 22 especies: 9 nuevas citas para Galicia (Harveylithon samoënse, Hydrolithon boreale, H. sargassi, Lithophyllum crouaniorum, Pneophyllum confervicola, P. coronatum, P. limitatum, P. myriocarpum y Titanoderma pustulatum var. confine); 8 citas (Hydrolithon boreale, Lithophyllum bathyporum. L. crouaniorum, Mesophyllum expansum, Pneophyllum myriocarpum, Titanoderma corallinae, T. laminariae y T. pustulatum var. confine) son novedad para Portugal continental y Phymatolithon lamii para norte de Portugal. Además, se dan a conocer 14 nuevas citas provinciales y 8 segundas citas provinciales. También se excluyen Lithophyllum duckerae y Phymatolithon purpureum de la flora del Atlántico ibérico.

Palabras clave: Algas coralinas, Atlántico ibérico, distribución, nuevas citas.

\section{Summary}

Coralline red algal flora of NW Iberia was re-visited in the framework of a recent doctoral thesis. The present study provides information about 22 species, 9 taxa are new records for Galicia (Harveylithon samoënse, Hydrolithon boreale, $H$. sargassi, Lithophyllum crouaniorum, Pneophyllum confervicola, P. coronatum, P. limitatum, P. myriocarpum and Titanoderma pustulatum var. confine). 8 are new for continental Portugal (Hydrolithon boreale, Lithophyllum bathyporum. L. crouaniorum, Mesophyllum expansum, Pneophyllum myriocarpum, Titanoderma corallinae, T. laminariae and T. pustulatum var. confine) and Phymatolithon lamii for northern Portugal. At province level, 14 taxa are new records and 8 are second records. In addition, Lithophyllum duckerae and Phymatolithon purpureum are excluded from the Atlantic Iberia flora.

Key words: Atlantic Iberia, coralline red algae, distribution, new records. 


\section{INTRODUCCIÓN}

Las algas rojas coralinas se caracterizan por la presencia de calcita como constituyente de la pared celular y actualmente se agrupan en la subclase Corallinophycidae de Rhodophyta (Le Gall \& Saunders 2007). Constituyen un grupo muy diverso y de amplia distribución que contiene más de 35 géneros y 749 especies reconocidas (GUIRY \& GUIRY 2020).

Para el noroeste de la Península Ibérica (Galicia y norte de Portugal) se conocen algunos trabajos sobre aspectos descriptivos o taxonómicos de diversas especies o géneros de las algas coralinas. Para las especies geniculadas, cabe destacar el estudio de Amphiroa vanbosseae (CREMADES et al. 1997) y sobre los géneros Corallina y Jania (BELTRÁN \& BÁRBARA 2003, PARdo et al. 2011, 2015, Lugilde et al. 2017, 2019). Para las no geniculadas, destacan los estudios sobre Lithophyllum y Mesophyllum (Hernández-Kantún et al. 2015a, b, PeÑA et al. 2015a). Otros estudios se han centrado en las especies formadoras de maërl en las costas gallegas (ADEY \& MCKIBBIN 1970, Peña \& BÁrbara 2004, 2008 a,b, 2009) y, más recientemente, en la diversidad críptica que se encuentra en estos hábitats (PEÑA \& BÁrBARA 2006, 2008a-b, PeÑa et al. 2011, 2014, 2015a, b, 2018, CARro et al. 2014, PARdo et al. 2014a, b, HeRnÁndez-Kantún et al. 2015b).

El conocimiento sobre algas bentónicas del noroeste ibérico fue recopilado por BÁRBARA et al. (2005a), ArAújo et al. (2009) y GAllardo et al. (2016), e información sobre las algas coralinas en LugILDE et al. (2016). Sin embargo, a pesar de estas investigaciones todavía no se dispone de un catálogo actualizado y se desconoce la distribución y el hábitat de varias especies de este grupo. Con este fin se abordó la realización de una flora (Lugilde YÁÑez 2020) en la que se hallaron nuevos registros y se realizaron correcciones que se dan a conocer en el presente artículo. Con ello se pretenden suplir deficiencias en el conocimiento florístico y completar los actuales inventarios de la biodiversidad de algas de Galicia y del norte de Portugal (BÁrbARA et al. 2005a-b, 2006, 2008, 2012, 2016, 2019, ArAúJo et al. 2009, BAÑón 2017).

\section{MATERIAL Y MÉTODOS}

Los muestreos se realizaron en Galicia y norte de Portugal (provincias de Lugo, A Coruña, Pontevedra, Minho, Douro Litoral y Beira Litoral) en el contexto de la tesis doctoral de Lugilde YÁÑEz (2020), y se realizaron mediante transectos desde el intermareal superior hasta el submareal $(<20 \mathrm{~m})$, tomando muestras representativas de todos los tipos de hábitats donde se desarrollan las algas coralinas. También se revisó material de distintos herbarios del área de estudio (SANT, COI y PO). Para la identificación de las muestras en el laboratorio se utilizó estereomicroscopio y microscopio óptico (MO). Para la realización de secciones del talo, se realizaron descalcificaciones en ácido acético diluido e inclusión en gelatina siguiendo la metodología descrita en Cremades et al. (1997). También se empleó microscopía electrónica de barrido (MEB, modelo JEOL JSM 6400, Universidade da Coruña), siguiendo la metodología de PEÑA et al. (2011).

Para algunos ejemplares se realizaron análisis moleculares. Para la extracción de ADN se utilizó el kit NucleoSpin ${ }^{\circledR}$ Tissue (Macherey-Nagel, $\mathrm{GmbH}$ and Co. KG, Alemania) siguiendo el protocolo del fabricante. Para la amplificación mediante PCR del gen plastídico psbA se siguió a BitTner (2009), PeÑa et al. (2015a) y a ANGLÉs D'Auriac et al. (2019), con los pares de primers: (psbAF1/psbAR2, psbAF1/psbA600R, psbA350F-psbA350R).

\section{RESULTADOS}

Se aporta información sobre la distribución de 22 especies de algas coralinas para Galicia y norte de Portugal. 9 especies son nuevas citas para Galicia: Harveylithon samoënse, Hydrolithon boreale, H. sargassi, Lithophyllum crouaniorum, Pneophyllum confervicola, $P$. coronatum, $P$. limitatum, $P$. myriocarpum y Titanoderma pustulatum var. confine y 8 especies como nuevas citas para Portugal: Hydrolithon boreale, Lithophyllum bathyporum. L. crouaniorum, Mesophyllum expansum, Pneophyllum myriocarpum, Titanoderma corallinae, T. laminariae y T. pustulatum var. confine. Phymatolithon lamii es nueva cita para 
el norte de Portugal. Además, se presentan 14 nuevas citas provinciales y 8 segundas citas provinciales. Finalmente se excluyen dos especies (Lithophyllum duckerae y Phymatolithon purpureum) de la flora del Atlántico ibérico.

\section{NUEVAS CITAS}

Corallina ferreyrae E.Y. Dawson, Acleto et Foldvik ( $=$ C. caespitosa R.H. Walker, J. Brodie et L.M. Irvine)

BEIRA LITORAL: Espinho-Aguda, 29TNF298411, 19-IX-2018, intermareal inferior expuesto, J. Lugilde \& D. Borges, SANT-Algae 33602. Primera cita provincial.

Harveylithon samoënse (Foslie) A. Rösler, Perfectti, V. Peña et J.C. Braga. (Figura 1)

LUGO: Playa de Peizás, 29TPJ396272, 9-II-2011, intermareal, V. Peña, C. Pardo, I. Bárbara \& I. Maneiro, confirmado mediante análisis molecular, SANT-Algae 33574. 19IV-2011, intermareal e intermareal inferior, sumergido en un canal, V. Peña \& A. Secilla, confirmados mediante análisis molecular, SANT-Algae 29138, 33575. PONTEVEDRA: Santa María de Oia, 29TNG97495, 17-IV-2011, intermareal, V. Peña \& A. Secilla, confirmado mediante análisis molecular, SANT-Algae 33576. Primera cita para Galicia.

Hydrolithon boreale (Foslie) Y.M. Chamberlain. (Figura 2)

LUGO: Playa de Peizás, 29TPJ396272, 22-V-2016, charca del intermareal inferior,
J. Lugilde, V. Peña, H. Kawai \& I. Bárbara, SANT-Algae 33610. A CORUÑA: Ría de A Coruña, Playa de Riazor, 29TNJ475020, 30III-2017, intermareal inferior, sobre Corallina officinalis. J. Lugilde, SANT-Algae 33593 como $H$. farinosum. Al sur de Illa do Valdabal, Islas de San Pedro, 29TNJ447024. 21-VI-2016, submareal (4 m), sobre Gongolariabaccata, A. García-Fernández \& I. Bárbara, SANT-Algae 33588. Punta Insua, 29TMH896354, 21-IV2017, submareal (4 m), sobre Pterocladiella capillacea, I. Bárbara \& A. García-Fernández, SANT-Algae 33590 como H. farinosum. Primera cita para Galicia. MINHO: Carreço (Montedor), 29TNG102209. 18-X-2018, intermareal inferior rocoso, sobre Corallina officinalis, J. Lugilde, SANT-Algae 33623. DOURO LITORAL: Leça da Palmeira, 29TNF242606, 06-IX-2018, intermareal inferior, sobre $C$. ferreyrae, J. Lugilde, SANT-Algae 33605. Primera cita para Portugal.

Hydrolithon sargassi (Foslie) Y.M. Chamberlain. (Figura 3)

LUGO: Playa Peizás, 29TPJ396272, 22V-2016, intermareal inferior fotófilo, sobre Pterocladiella capillacea, J. Lugilde, V. Peña, H. Kawai \& I. Bárbara, SANT-Algae 33611. Illa Pancha, 29TPJ581240. 12-VII-2018, submareal (1 m), sobre Gongolaria baccata, A. García-Fernández \& I. Bárbara, SANTAlgae 33609. A CORUÑA: Ría de A Coruña, Playa de A Xunqueira, 29TNJ528035, 17-XI2016, submareal (5 m), epífita de Desmarestia
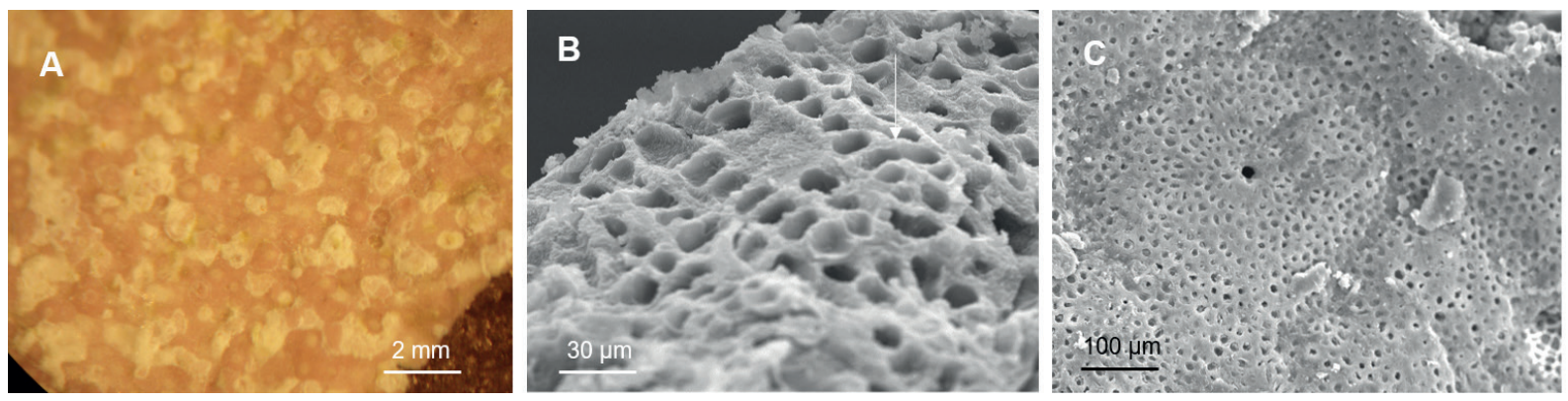

Figura 1. Harveylithon samoënse. A. Talo epilítico en vista superficial, con conceptáculos uniporados en superficie. B. Sección transversal del talo formado por 8-10 capas corticales y fusiones celulares (flecha) entre células de filamentos contiguos. C. Conceptáculo uniporado en vista superficial. (B-C) microscopía electrónica de barrido, MEB.

Figure 1. Harveylithon samoënse. A. Epilithic thallus with uniporate conceptacles in surface view. B. Cross-section of the thallus showing 8-10 cortical layers and fusion cells (arrow) between cells of contiguous filaments. C. Uniporate conceptacle in surface view. (B-C) scanning electron miscrocope, SEM. 

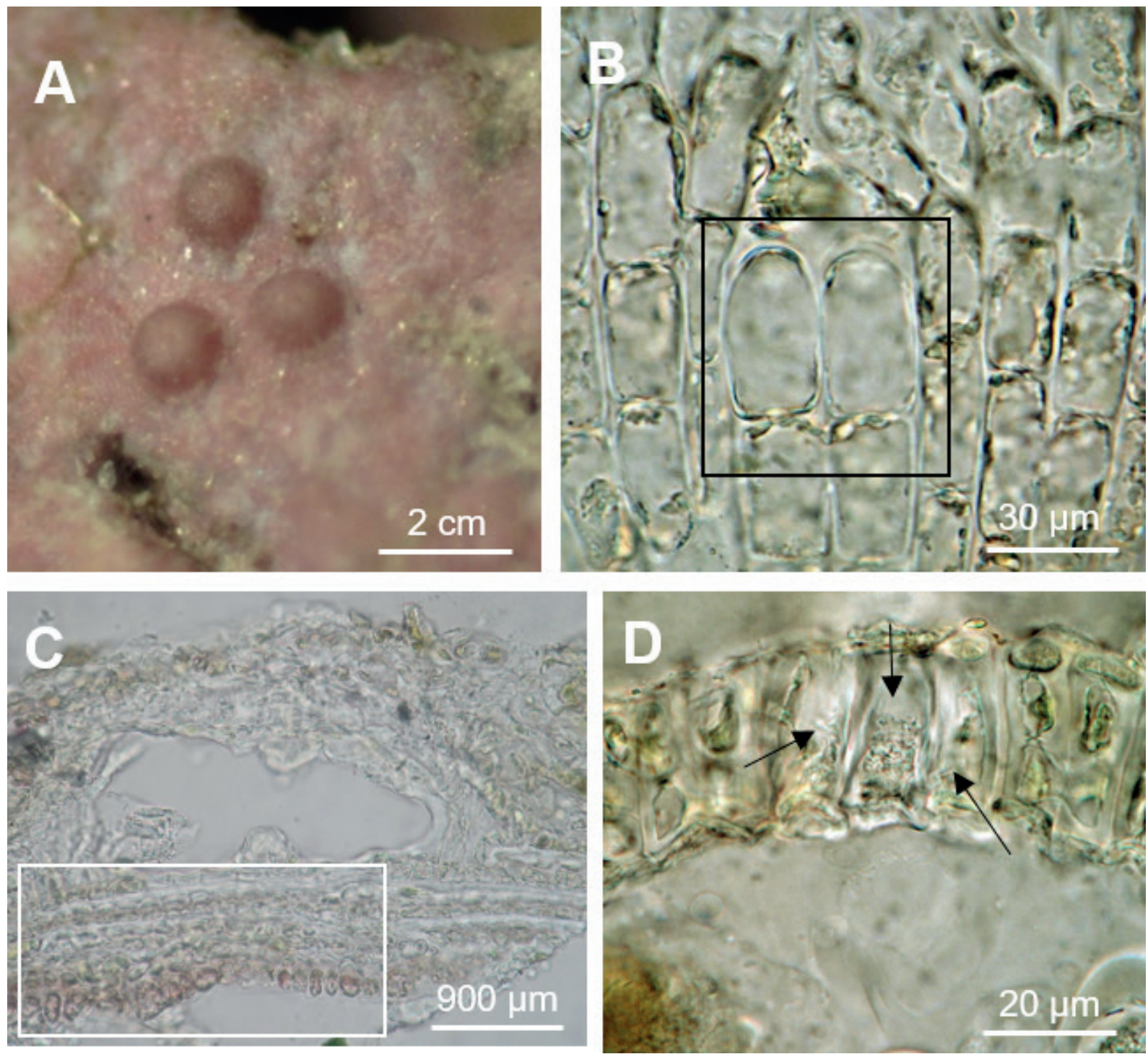

Figura 2. Hydrolithon boreale. A. Hábito epilítico. Conceptáculos uniporados en vista superficial. B. Tricocitos en pares terminales en el filamento, en vista superficial (recuadro). C. Sección transversal del talo dímero, con un conceptáculo uniporado vacío y numerosas capas celulares superpuestas (recuadro). D. Células del canal del poro perpendiculares al techo del conceptáculo, con 3 células centrales alargadas (sección transversal, flechas). (B-D) material descalcificado, microscopía óptica, MO.

Figure 2. Hydrolithon boreale. A-B. Epilithic habit. Uniporate conceptacles in surface view. C. Trichocytes grouped in terminal pairs (square), in surface view. C. Cross section of a dimerous thallus, with an empty conceptacle and vegetative overlapping layers below (square). D. Cells lining the canal pore perpendicular to the roof surface, showing three central and enlarged cells (cross section, arrows). (B-D) decalcified material, optical microscopy, MO.

aculeata, J. Lugilde \& I. Bárbara, SANT-Algae 33596. Primera cita para Galicia.

\section{Lithophyllum bathyporum A. Athanasiadis} et D.L. Ballantine

LUGO: Ensenada de Cegoñas, 29TPJ515240, 25-III-2016, epilítica, intermareal medio-inferior, J. Lugilde, SANT-Algae
33258. San Cibrao, 29TPJ257391, 01-IX-2017, epilítica, intermareal medio-inferior, J. Lugilde, SANT-Algae 33617, 33618. Segunda cita provincial, después de HERNÁNDEZ-KANTÚN et al. (2015a). MINHO: Viana do Castelo, 29TNG117168, 29-IX-2018, intermareal medio-inferior, J. Lugilde. SANT-Algae 33295. DOURO LITORAL: Apúlia, 29TNF186916, 

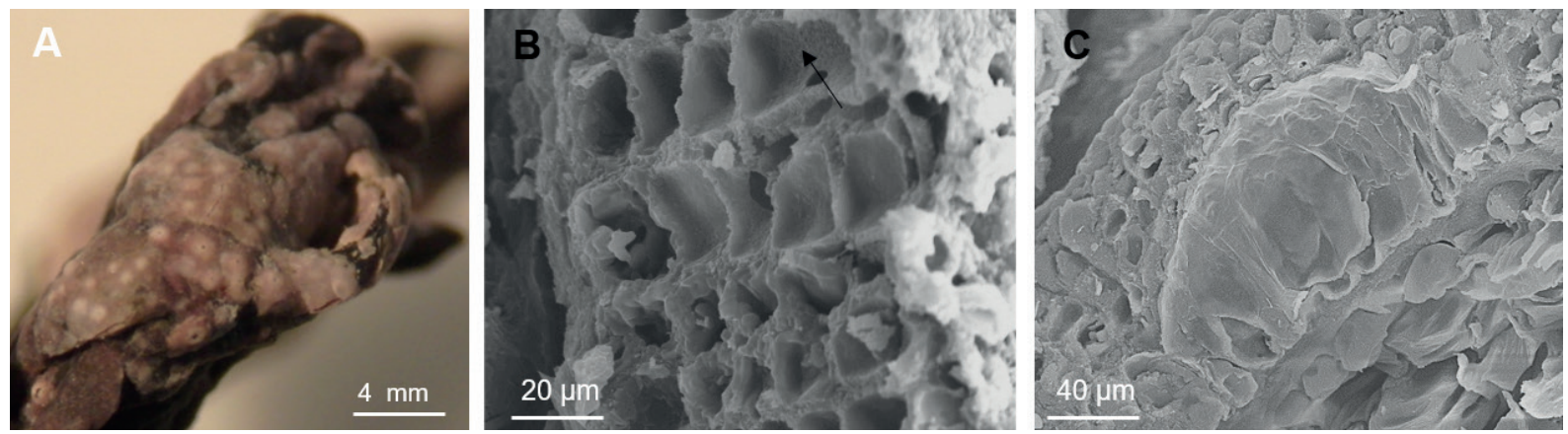

Figura 3. Hydrolithon sargassi. A. Talos epífitos sobre Gongolaria baccata, en vista superficial.-B. Sección transversal mostrando varias capas de células corticales (4-5) y fusión celular entre filamentos vegetativos contiguos (flecha). C. Sección transversal de un conceptáculo uniporado inmerso en el talo, probablemente de esporocistes. (B-C) MEB.

Figure 3. Hydrolithon sargassi. A-B. Epiphytic thalli on Gongolaria baccata. C. Cross-section of the thallus showing several layers of cortical cells and a fusion cell between contiguous vegetative filaments (arrow). C. Uniporate conceptacle immersed in the thallus, probably sporangial. (B-C) SEM.
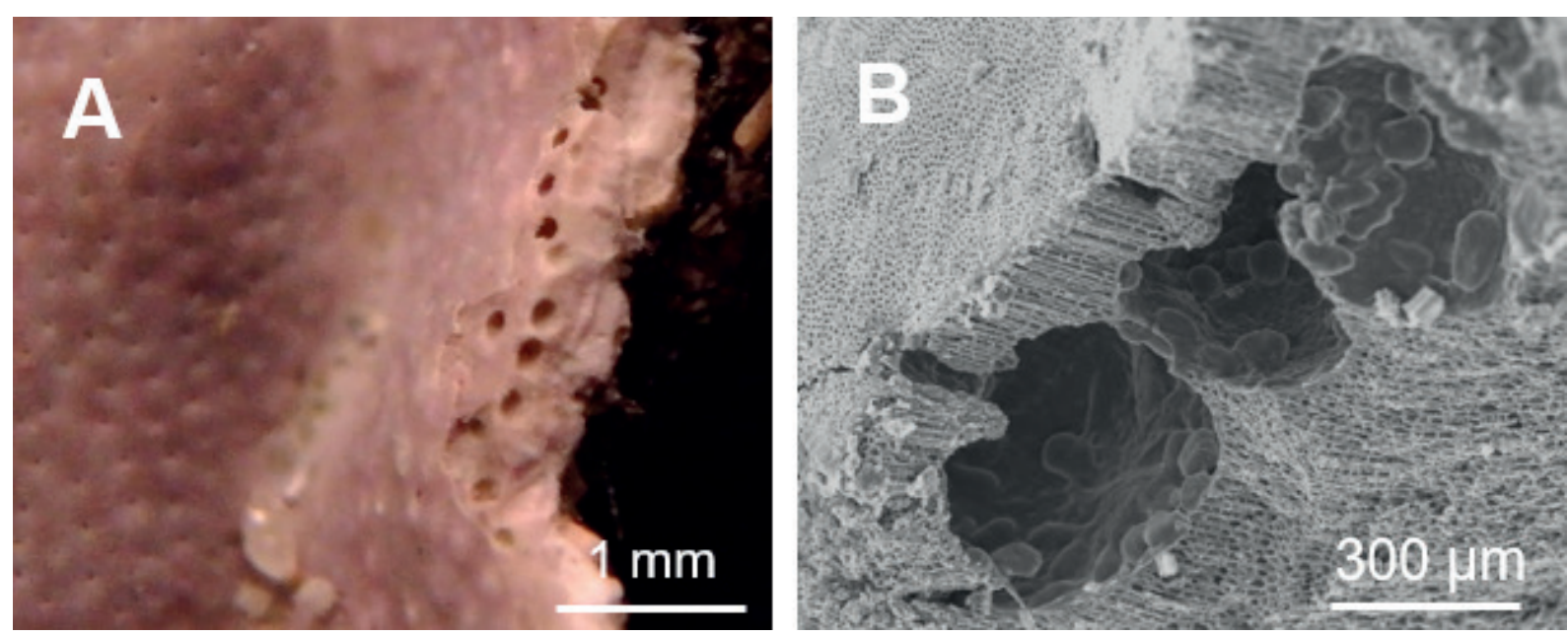

Figura 4. Lithophyllum crouaniorum. A. Talo en vista superficial mostrando conceptáculos uniporados en densos grupos con el techo blanco y con el margen definido blanco. B. Conceptáculos uniporados de bisporocistes en sección transversal con la cámara redondeada. (B) MEB.

Figure 4. Lithophyllum crouaniorum. A. Surface view of the thallus showing a flat surface with uniporate conceptacles arranged in groups and white ceiling and a defined, white margin. B. Cross-section of the thallus showing uniporate bisporangial conceptacles with rounded chambers (B) SEM.

27-IX-2018, intermareal medio-inferior, J. Lugilde, SANT-Algae 33351. Praia de Lavadores, 29TNF278531, 07-IX-2018, intermareal medio-inferior, J. Lugilde, SANT-Algae 33295. Primera cita para Portugal.

Lithophyllum crouaniorum Foslie. (Figura 4) LUGO: Punta Galiño, San Ciprián, 29TPJ231415, 21-VII-2015, submareal (6 m), sobre roca en ambiente umbrío, I. Bárbara, A. García-Fernández \& V. García-Redondo, SANT-Algae 33616. A CORUÑA: Ría de
A Coruña, Playa de Riazor, 29TNJ475020. 30-III-2017, submareal (6 m), J. Lugilde, SANT-Algae 33594. Playa de Barizo, 29TNH102958. 13-VII-2017, submareal (4-5 $\mathrm{m})$, epífito de Corallina officinalis, I. Bárbara \& A. García-Fernández, SANT-Algae 33580. Primera cita para Galicia. MINHO: Viana do Castelo, 29TNG117168, 29-IX-2018, intermareal inferior, J. Lugilde, M. Rubal \& C. Torres. SANT-Algae 33624. DOURO LITORAL: Vila do Conde, 29TNF204781, 26-IX2018, epífito de Lithophyllum sp. J. Lugilde \& 

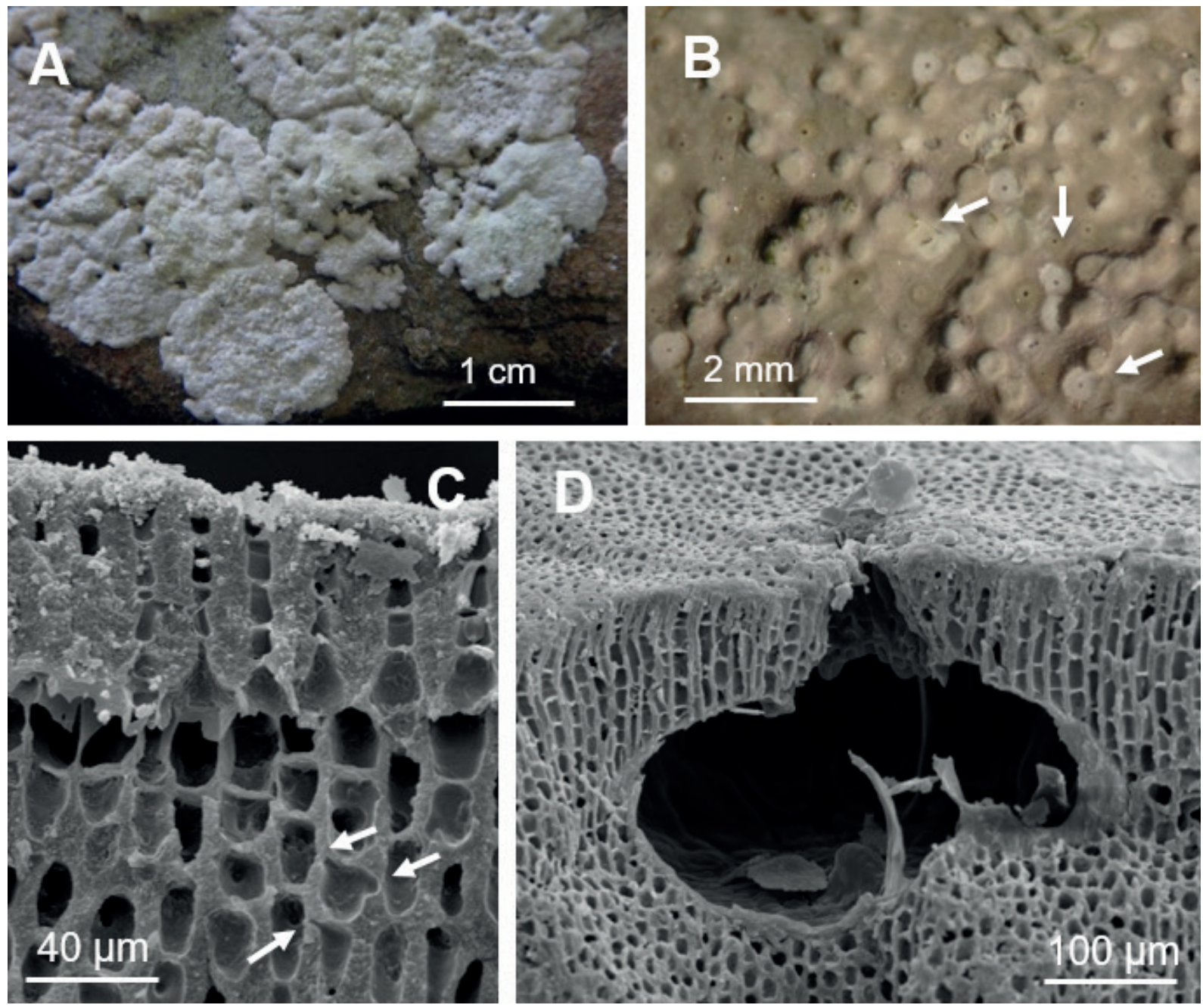

Figura 5. Lithophyllum orbiculatum. A. Talos epilíticos incrustantes. B. Aspecto de los conceptáculos uniporados en vista superficial, algunos emergentes y otros senescentes (flechas). C. Sección del talo con la disposición de las células corticales unidas por sinapsis secundarias (flechas). D. Sección transversal mostrando un conceptáculo uniporado de esporocistes vacío, con el canal del poro cónico. C-D (MEB).

Figure 5. Lithophyllum orbiculatum. A. Epilithic, crustose thalli. B. Surface view of the thallus showing uniporate conceptacles at different stages (arrows). C. Cross-section of the thallus showing several layers of cortical cells, joined by secondary pit-connections (arrows). D. Cross-section of an empty sporangial conceptacle showing conical pore canal. C-D (SEM).

D. Borges, SANT-Algae 33606. Primera cita para Portugal.

Lithophyllum orbiculatum (Foslie) Foslie. (Figura 5)

LUGO: Isla Pancha, 29TPJ581240. 21-V2016, intermareal medio-superior, J. Lugilde. SANT-Algae 33270. Primera cita provincial. A CORUÑA: Ría de A Coruña, Al Norte de Isla Castelo, 29TNJ533048. 26-I-2016, intermareal medio, J. Lugilde, V. Peña \& I. Bárbara,
SANT-Algae 33197. Ría de Betanzos, Ensenada de Lourido, 29TNJ597034. 12IV-2017, intermareal inferior, J. Lugilde, SANT-Algae 33310. Primera cita provincial. DOURO LITORAL: Apúlia, 29TNF186916. 27-IX-2018, intermareal medio-inferior. J. Lugilde, SANT-Algae 33353. Leça da Palmeira, 29TNF242606, 06-IX-2018, intermareal medio, J. Lugilde, SANT-Algae 33377. Vila do Conde, 29TNF204781, 26-IX-2018, intermareal medio-superior, J. Lugilde \& D. Borges, 

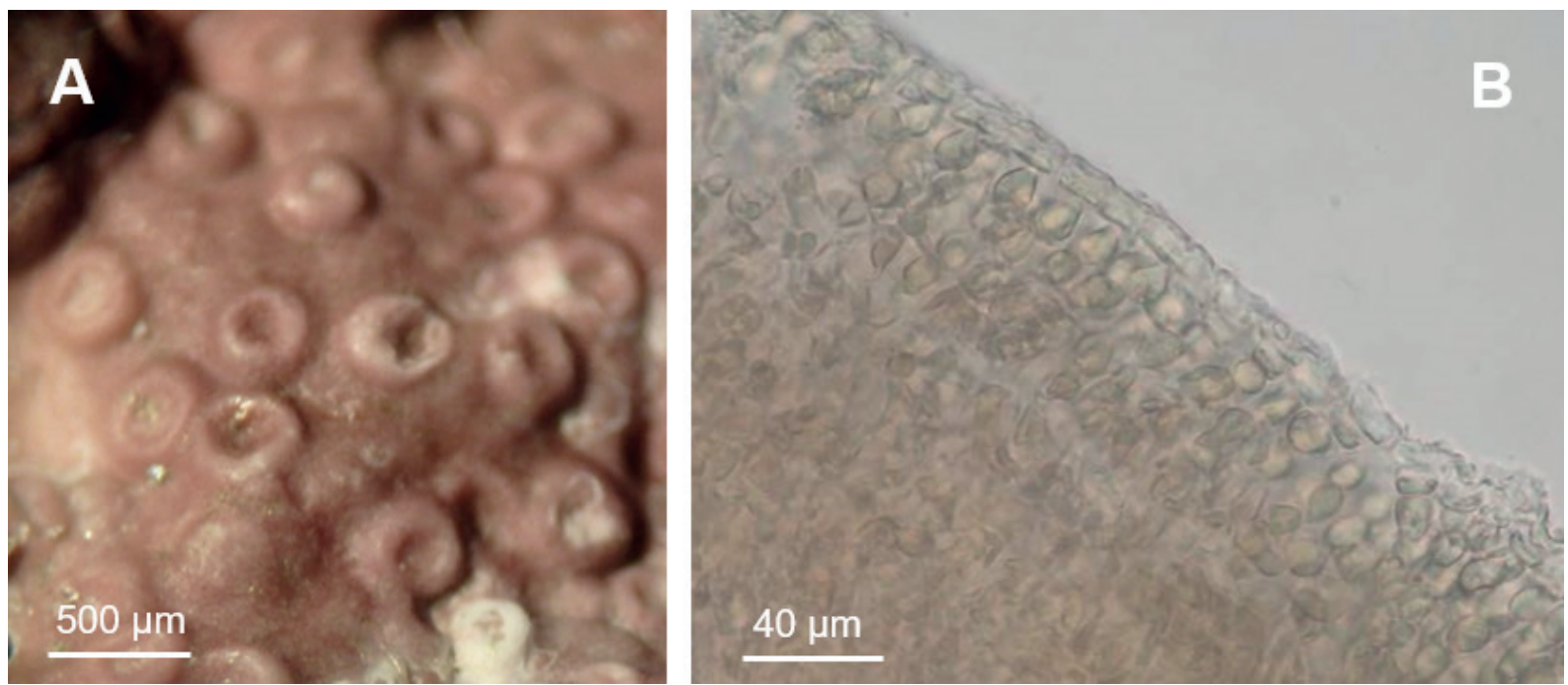

Figura 6. Mesophyllum alternans. A. Conceptáculos de esporocistes con la placa multiporada hundida, en vista superficial. B. Sección transversal del talo con varias capas de células corticales, células iniciales subepitalinas más grandes que las corticales subyacentes y una capa de células epitalinas aplanadas. (B) MO.

Figure 6. Mesophyllum alternans. A. Surface view of multiporate sporangial conceptacles with the sunken pore plate. B. Cross section of the thallus showing several layers of cortical cells, subepithallial initial cells larger than cells subtending them and a single layer of flattened epithallial cells. (B) MO.

SANT-Algae 33301. Primera cita provincial. BEIRA LITORAL: Espinho-Aguda, 29TNF298411, 19-IX-2018, intermareal medio-inferior, J. Lugilde \& D. Borges, SANT-Algae 33357. Primera cita provincial.

\section{Lithophyllum stictiforme (J.E. Areschoug) Hauck \\ DOURO LITORAL: Apùlia, 29TNF186916, 26-IX-2018, submareal (9 m), J. Franco, SAN- T-Algae 33619. Presenta la morfología externa característica descrita para esta especie, aunque PEZZOLESI et al. (2019) advierten de la diver- sidad críptica encontrada bajo L. stictiforme en el Mediterráneo. Primera cita provincial.}

Mesophyllum alternans (Foslie) Cabioch et M.L. Mendoza.(Figura 6)

LUGO: Playa de Peizás, 29TPJ396277, 22V-2016, intermareal medio-inferior fotófilo, J. Lugilde, V. Peña, H. Kawai \& I. Bárbara, SANT-Algae 33181, 33182. Segunda cita provincial, después de BÁRBARA et al. (2016). PONTEVEDRA: Ría de Vigo, Islas Cíes, Ensenada de Fornos, 29TNG082756. 04-V-2016, submareal (5 m), V. Peña \& P. Díaz, SANTAlgae 33633. Primera cita provincial. DOURO
LITORAL: Praia Aguda, 29TNF291439, 11-IX-2018, intermareal inferior (0-1 m), J. Lugilde \& D. Borges, SANT-Algae 33348. Primera cita provincial.

Mesophyllum expansum (Philippi) Cabioch et Mendoza

MINHO:Praia Aguçadoura, 29TNF180862, 09-IX-2018, intermareal inferior, J. Lugilde \& D. Borges, SANT-Algae 33306. DOURO LITORAL: Vila do Conde, 29TNF204781. 26-IX-2018, intermareal medio, J. Lugilde \& D. Borges, SANT-Algae 33389. BEIRA LITORAL: Espinho-Aguda, 29TNF298411, 19-IX-2018, intermareal inferior, J. Lugilde \& D. Borges, SANT-Algae 33359. Primera cita para Portugal.

Phymatolithon boreale W.H. Adey, J.J. Hernández-Kantún et P.W. Gabrielson

LUGO: Playa de Peizás, 29TPJ396272, 22V-2016, intermareal medio-inferior, J. Lugilde, V. Peña, H. Kawai \& I. Bárbara, SANT-Algae 33612, 33613. A Pena, 29TPJ454248, 24-VIII2015, intermareal medio-inferior, J. Lugilde, SANT-Algae 33608. Segunda cita provincial, después de Adey et al. (2018). A CORUÑA: Ría de A Coruña, Islas de San Pedro, 

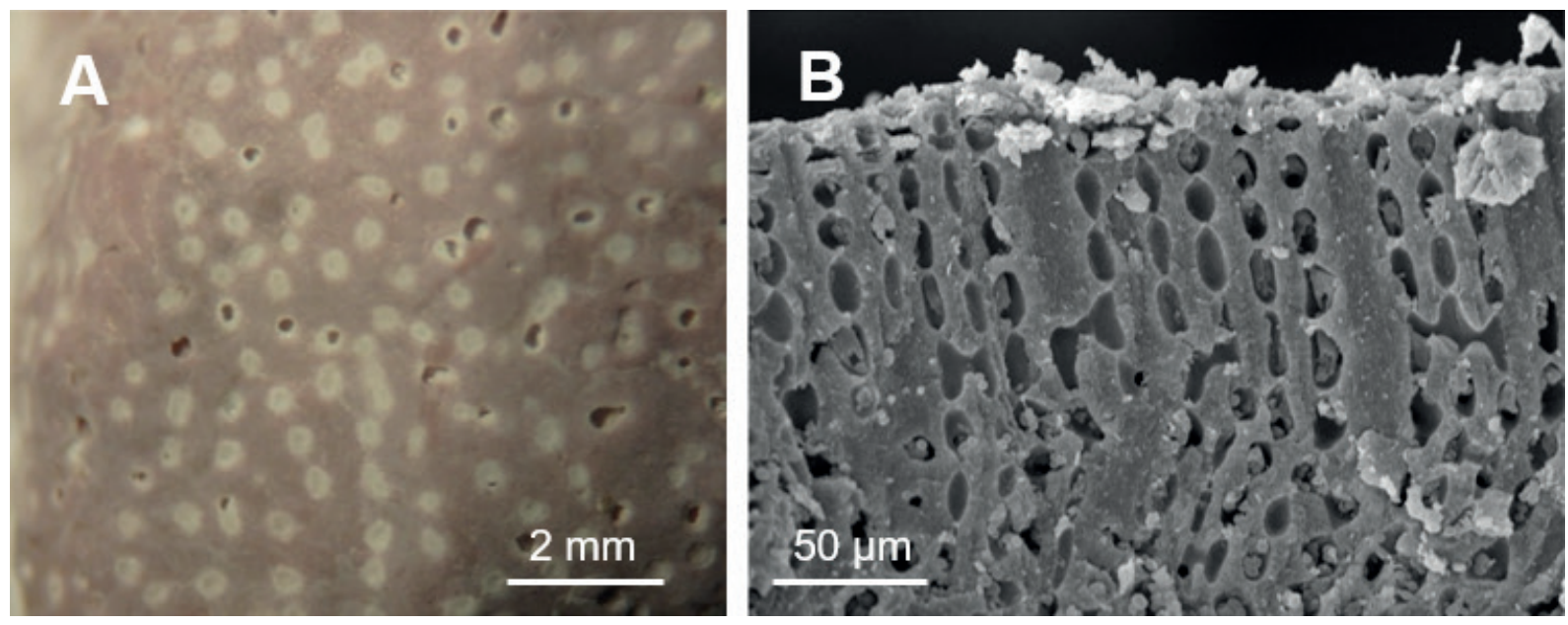

Figura 7. Phymatolithon lamii. A. Superficie del talo plana con conceptáculos de esporocistes multiporados senescentes, con algunas placas del poro hundidas y otras con techo blanco. B. Sección transversal del talo con varias capas de células corticales, unidas entre sí por fusiones celulares y 1-2 estratos de células epitalinas en domo. (B) MEB.

Figure 7. Phymatolithon lamii. A. Flat surface thallus showing senescent multiporate sporangial conceptacles, some of them senescent with sunken pore plates and others with white pore plate. B. Cross section of the thallus showing several layers of cortical cells with fusion cells and 1-2 layers of domed epithallial cells. (B) SEM.
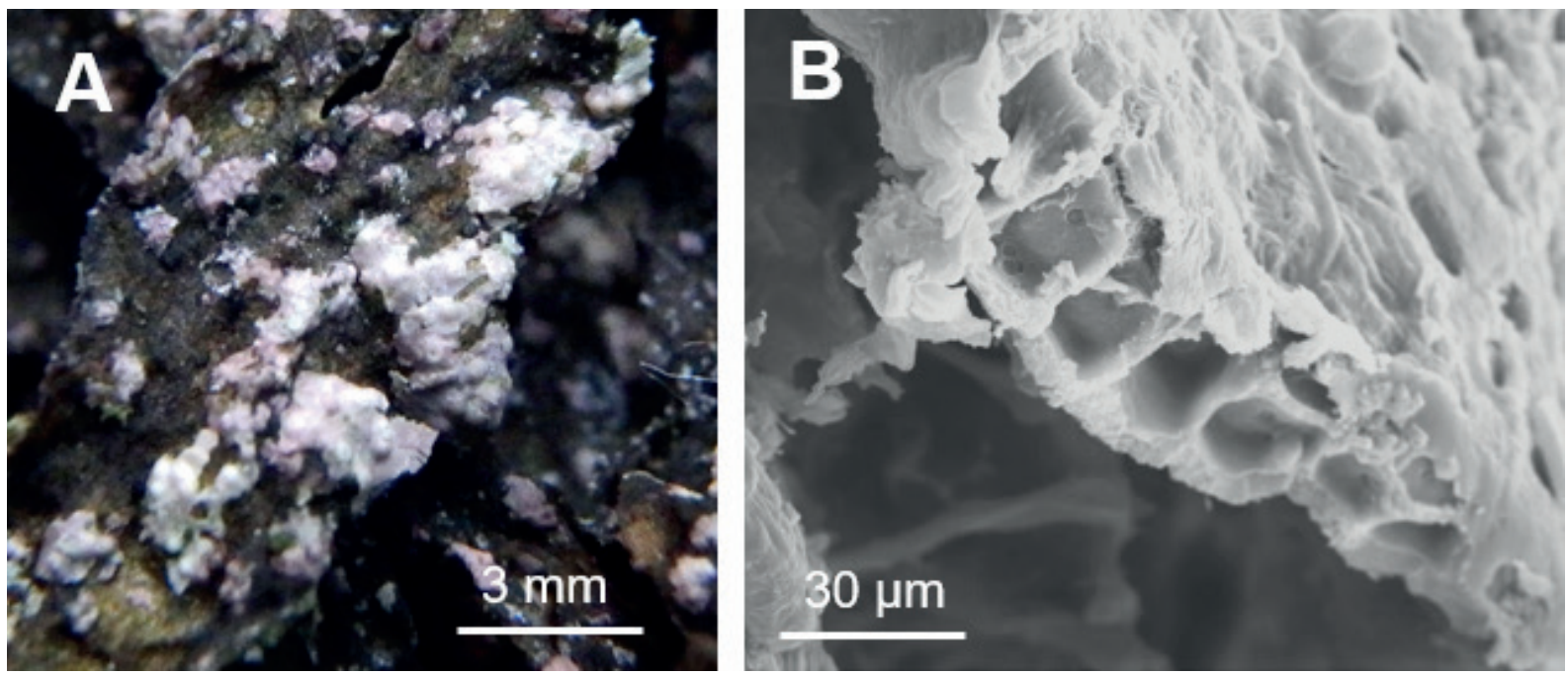

Figura 8. Pneophyllum confervicola. A. Hábito epífito sobre Chondrus crispus. B. En sección transversal, talo biestratificado, con células basales redondeadas y células epitalinas aplanadas. (B) MEB.

Figure 8. Pneophyllum confervicola. A. Epiphytic on Chondrus crispus. B. Cross section of bistratose thallus, with rounded basal cells and flat epithallial cells. (B) SEM.

Al sur de Illa do Valdabal, 29TNJ444027, 21-IV-2016, submareal (4m), epilítico, A. García-Fernández \& I. Bárbara, SANTAlgae 33586. Segunda cita provincial, después de Adey et al. (2018). PONTEVEDRA: Cala Major, Ría de Pontevedra, 29TNG109955, 31-III-2018, intermareal inferior, J. Lugilde, SANT-Algae 33630. Primera cita provincial. MINHO: Viana do Castelo, 29TNG117168,
29-IX-2018, intermareal medio-inferior, J. Lugilde, M. Rubal \& C. Torres, SANT-Algae 33625-33627. Segunda cita provincial, después de Adey et al. (2018). DOURO LITORAL: Vila do Conde, 29TNF204781, 26-IX-2018, intermareal medio-superior, J. Lugilde \& D. Borges, SANT-Algae 33607. Praia Aguda, 29TNF291439, 11-IX-2018, intermareal inferior, J. Lugilde \& D. Borges, SANT-Algae 
33601. Apúlia, 29TNF186916, 27-IX-2018, intermareal medio, fotófilo y bajo influencia de arena, J. Lugilde \& M. Rubal, SANT-Algae 33620. Primera cita provincial. BEIRA LITORAL: Espinho-Aguda, 29TNF298411, 19-IX2018, intermareal inferior y medio superior, J. Lugilde \& D. Borges, SANT-Algae 33603. Primera cita provincial.

Phymatolithon lamii (Me. Lemoine) Y.M. Chamberlain. (Figura 7)

LUGO: Ría de Viveiro, Insua de Area, 29TPJ141393, 22-V-2016, submareal (5 m), J. Lugilde, V. Peña, H. Kawai \& I. Bárbara, SANT-Algae 33315. Praia de Peizás, 29TPJ396277, 22-V-2016, charca rocosa del intermareal medio, J. Lugilde, V. Peña, H. Kawai \& I. Bárbara, SANT-Algae 33185. Segunda cita provincial, después de PEÑA et al. (2015a). A CORUÑA: Playa de Barizo, 29TNH102958, 06-IV-2016, submareal (2-3 m), A. García-Fernández \& I. Bárbara, confirmado mediante análisis molecular, SANT-Algae 33168. Seaia, 29TNH103963, 15-IV-2017, intermareal medio-inferior expuesto, J. Lugilde, SANT-ALGAE 33395. Ría de A Coruña, Playa de A Xunqueira, 29TNJ528035, 18-IV2016, submareal (5 m), A. García-Fernández \& I. Bárbara, confirmado mediante análisis molecular, SANT-Algae 33595. Segunda cita provincial, después de PeÑa et al. (2015a). PONTEVEDRA: Ría de Vigo, Islas Cíes, Ensenada de Fornos, 29TNG082756, 04-V2016, submareal (13 m), roca con bolos grandes y arena y cascajo entre ellos, V. Peña \& P. Díaz, SANT-Algae 33632. Primera cita provincial. MINHO: Viana do Castelo, 29TNG117168, 29-IX-2018, intermareal inferior rocoso, J. Lugilde, M. Rubal \& C. Torres, SANT-Algae 33628. DOURO LITORAL: Apúlia, 29TNF186916, 27-IX-2018, intermareal medio-inferior, J. Lugilde, SANT-Algae 33354. Praia Aguçadoura, 29TNF180862, 9-IX-2018, intermareal inferior, J. Lugilde \& D. Borges, SANT-Algae 33599. BEIRA LITORAL: Buarcos, 29TNE103549, 14-X-2018, intermareal rocoso expuesto, J. Lugilde, SANT-Algae 33578. Primera cita para el norte de Portugal

Phymatolithon lenormandii (Areschoug) Adey

DOURO LITORAL: Vila do Conde, 29TNF204781, 26-IX-2018, intermareal medio-superior, J. Lugilde \& D. Borges, SANTAlgae 33302. Primera cita provincial.

Pneophyllum confervicola (Kützing) Y.M. Chamberlain. (Figura 8)

A CORUÑA: Playa de Barizo, 29TNH102958, 13-VII-2017, submareal (4-5 m), epífita de Dictyota dichotoma,
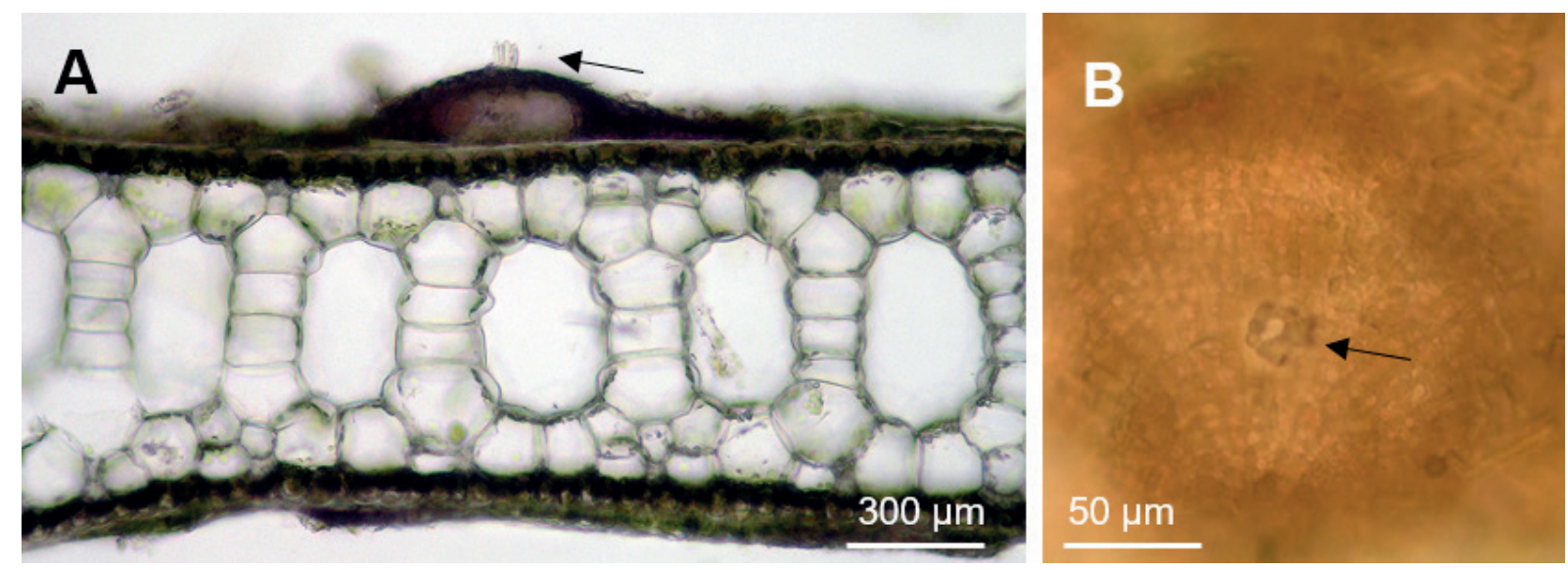

Figura 9. Pneophyllum coronatum. A. Sección transversal de un talo epífito sobre una hoja de Zostera marina, mostrando un conceptáculo uniporado de esporocistes emergente. En el poro del conceptáculo se observa una corona de filamentos (flecha). B. Detalle de la corona de filamentos presente en conceptáculos (flecha), en visión superficial. (A-B) MO.

Figure 9. Pneophyllum coronatum. A. Cross-section of the thallus overgrowing a leave of Zostera marina with an uniporate sporangial conceptacle protruding, and a corona of filaments in the pore (arrow). B. Detail of the corona of filaments in the pore (arrow), in surface view. (A-B) MO. 

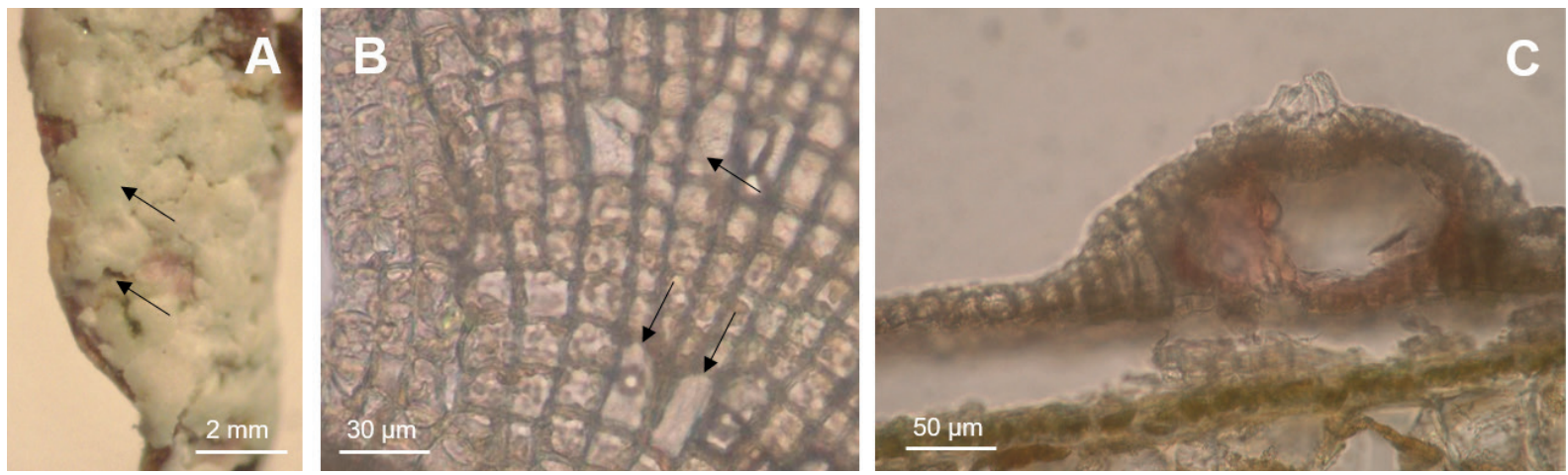

Figura 10. Pneophyllum limitatum. A. Talo epífito sobre Pterocladiella capillacea, con los conceptáculos uniporados planos, ligeramente emergentes (flechas). B. Tricocitos individuales en vista superficial, terminales e intercalares (flechas). C. Conceptáculo uniporado de tetrasporocistes emergente en detalle con corona de filamentos y talo biestratificado. (B-C) MO.

Figure 10. Pneophyllum limitatum. A. Epiphytic thallus on Pterocladiella capillacea, with uniporate Conceptacles, slightly emerged (arrows). B. Terminal and intercalary trichocytes in surface view (arrows). C. Cross-section of a tetrasporangial conceptacle protruding, corona of filaments and bistratose thallus. (B-C) MO.
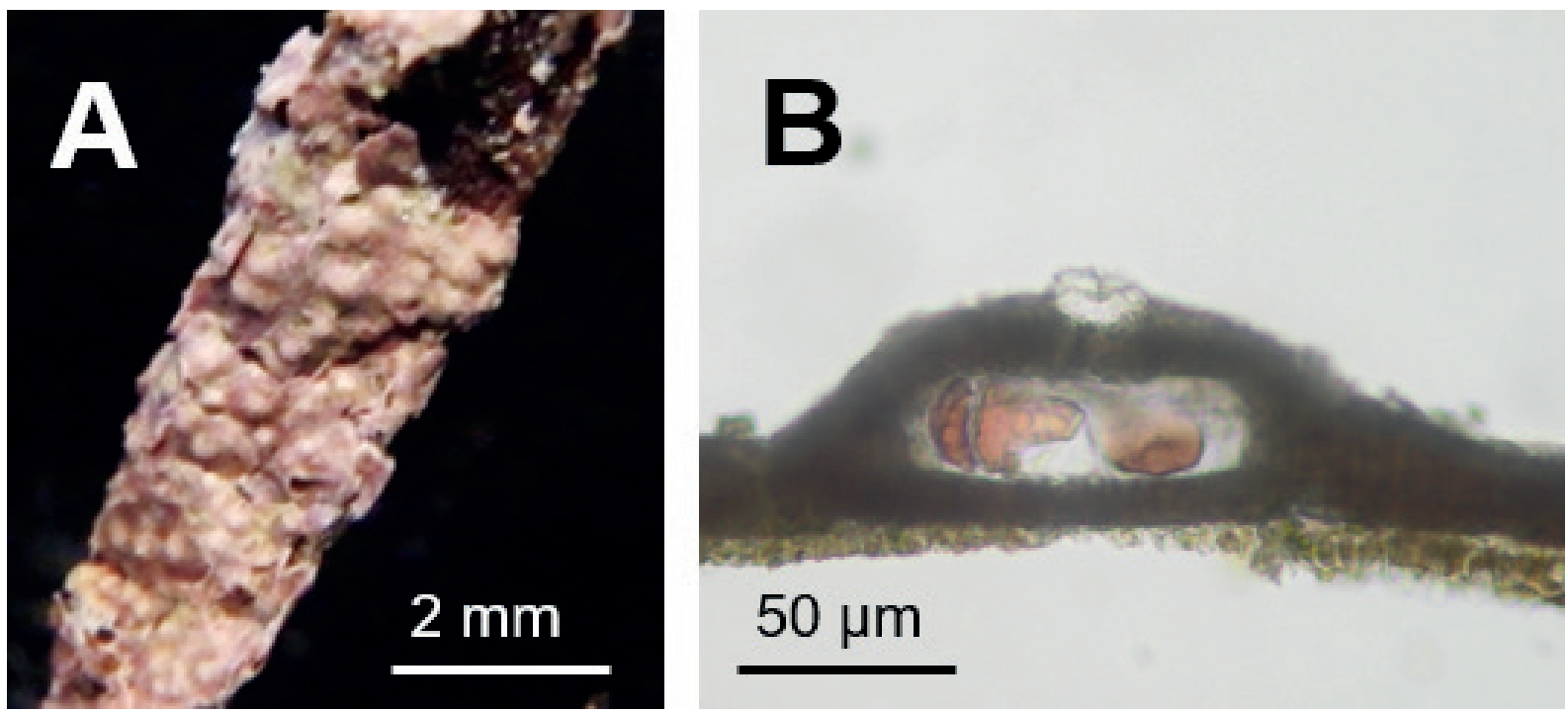

Figura 11. Pneophyllum myriocarpum. A. Talos epífitos sobre Chondrus crispus. B. Conceptáculos de tetrasporocistes uniporados, con collar hialino y con la placa del poro plana. (B) MO.

Figure 11. Pneophyllum myriocarpum. A. Epiphytic thalli on Chondrus crispus. B. Tetrasporangial uniporate conceptacles, with hyaline collar and sunken plate pore. (B) MO.

A. García-Fernández \& I. Bárbara, SANT-Algae 33581. Primera cita para Galicia.

\section{Pneophyllum coronatum (Rosanoff) Penrose} in Y.M. Chamberlain. (Figura 9)

A CORUÑA: Ría de Ferrol, Piedra de la Reina, 29TNJ569116, 11-XI-2015, submareal(2 m), sobre Zostera marina, V. García-Redondo, A. García-Fernández \& I. Bárbara, SANT-Algae 33591. Ensenada del embarcadero de Sálvora, Ría de Arousa, 29TMH997021, 20-VII-2016, submareal (2 m), sobre Z. marina, V. GarcíaRedondo, I. Bárbara \& A. García-Fernández, SANT-Algae 33585. Primera cita para Galicia.

Pneophyllum limitatum (Foslie) Y.M. Chamberlain. (Figura 10)

A CORUÑA: Ría de A Coruña, Playa de A Xunqueira, 29TNJ528035, 17-XI-2016, submareal (4 m), epífita de Gongolaria baccata, J. Lugilde \& I. Bárbara, SANT-Algae 33597. Ría de Ferrol, Piedra de la Reina, 29TNJ539123, 

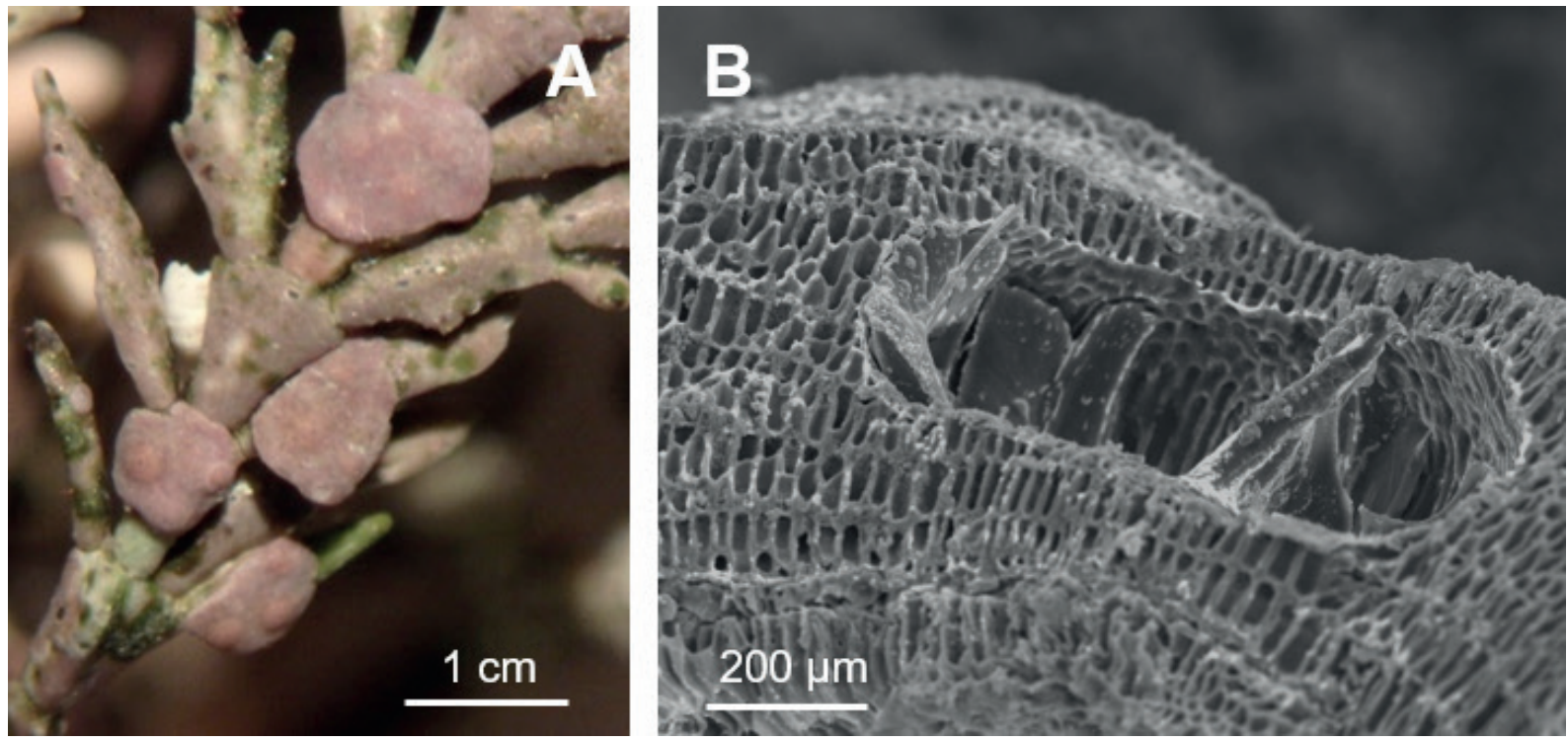

Figura 12. Titanoderma corallinae. A. Hábito epífito sobre Ellisolandia elongata. B. Sección del talo con filas de células corticales en empalizada y conceptáculo de esporocistes uniporado inmerso en el talo. (B) MEB.

Figure 12. Titanoderma corallinae. A. Epiphytic on Ellisolandia elongata. B. Cross section of thallus showing cortical layers of palisade cells and a uniporate sporangial conceptacle inmersed within the thallus. (B) SEM.

14-X-2015, submareal (4 m), epífita de algas, V. García-Redondo \& I. Bárbara, SANT-Algae 33592. Primera cita para Galicia.

Pneophyllum myriocarpum (P.L. Crouan et H.M. Crouan) Y.M. Chamberlain. (Figura 11)

A CORUÑA: Ría de A Coruña, Playa de A Xunqueira, 29TNJ528035, 17-XI-2016, submareal (6 m), epífito sobre Gongolaria baccata, J. Lugilde \& I. Bárbara, SANT-Algae 33598. Primera cita para Galicia. DOURO LITORAL: Praia Aguçadoura, 29TNF180862, 09-IX-2018, intermareal inferior expuesto, con influencia arenosa, epífito con Melobesia membranacea, J. Lugilde \& D. Borges, SANTAlgae 33600. Primera cita para Portugal.

Titanoderma corallinae (P.L. Crouan et H.M. Crouan) Heydrich. (Figura 12)

DOURO LITORAL: Apúlia, 29TNF186916. 27-IX-2018, intermareal inferior-medio, sobre Corallina officinalis, J. Lugilde \& M. Rubal, SANT-Algae 33621. BEIRA LITORAL: Espinho-Aguda, 29TNF298411, 19-IX-2018, intermareal inferior, sobre algas coralinas geniculadas, J. Lugilde \& D. Borges, SANT-Algae 33604. Primera cita para Portugal.
Titanoderma laminariae (P.L. Crouan et H.M. Crouan) Y.M. Chamberlain. (Figura 13)

A CORUÑA: Playa de Barizo, 29TNH102958, 31-I-2018, submareal (3-4 m), sobre Gongolaria baccata. A. García-Fernández \& I. Bárbara, SANT-Algae 33582. Segunda cita provincial después de BÁRBARA et al. (2005a). PONTEVEDRA: Cala Major, Ría de Pontevedra, 29TNG109955. 31-III-2018, intermareal inferior, en la base de Bifurcaria bifurcata, J. Lugilde, SANT-Algae 33631. Primera cita provincial. MINHO: Viana do Castelo, 29TNG117168. 29-IX-2018, intermareal inferior, sobre Pterocladiella capillacea y G. baccata, J. Lugilde, M. Rubal \& C. Torres, SANT-Algae 33629. Primera cita para Portugal.

Titanoderma pustulatum var. confine (P.L. Crouan et H.M. Crouan) Y.M. Chamberlain. (Figura 14)

LUGO: Playa de Peizás, 29TPJ396272, 25 VIII-2018, 22-V-2016, intermareal inferior, expuesto, sobre Gongolaria baccata, Corallina officinalis, A. García-Fernández \& I. Bárbara, SANT-Algae 33614, 33615. A CORUÑA: Ría de Ares y Betanzos, Dexo, 29TNJ541055, 19-IV-2016, submareal (3 m), sobre hilo de 

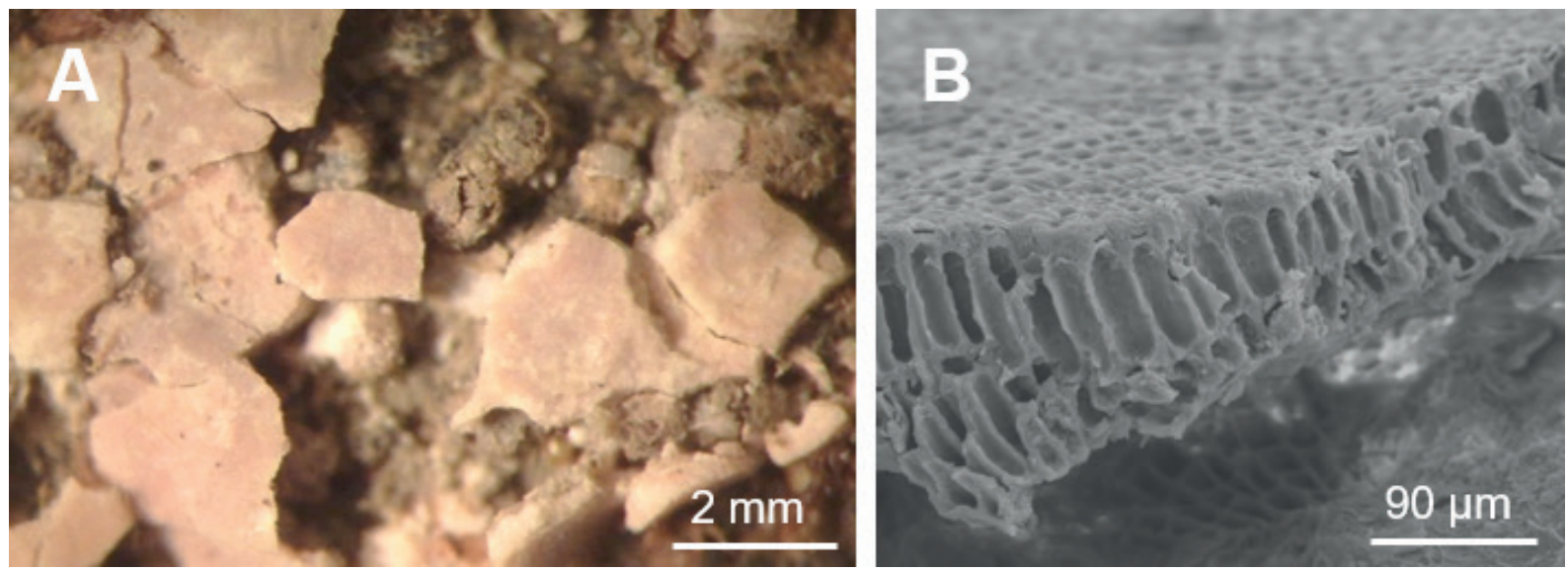

Figura 13. Titanoderma laminariae. A. Talo fragmentado epífito sobre Laminaria sp. B. Talo en sección transversal mostrando varias capas de células corticales en empalizada. (B) MEB.

Figure 13. Titanoderma laminariae. A. Fragmented thallus epiphytic on Laminaria sp. B. Cross section of the thallus showing several layers of palisade cortical cells. (B) SEM.
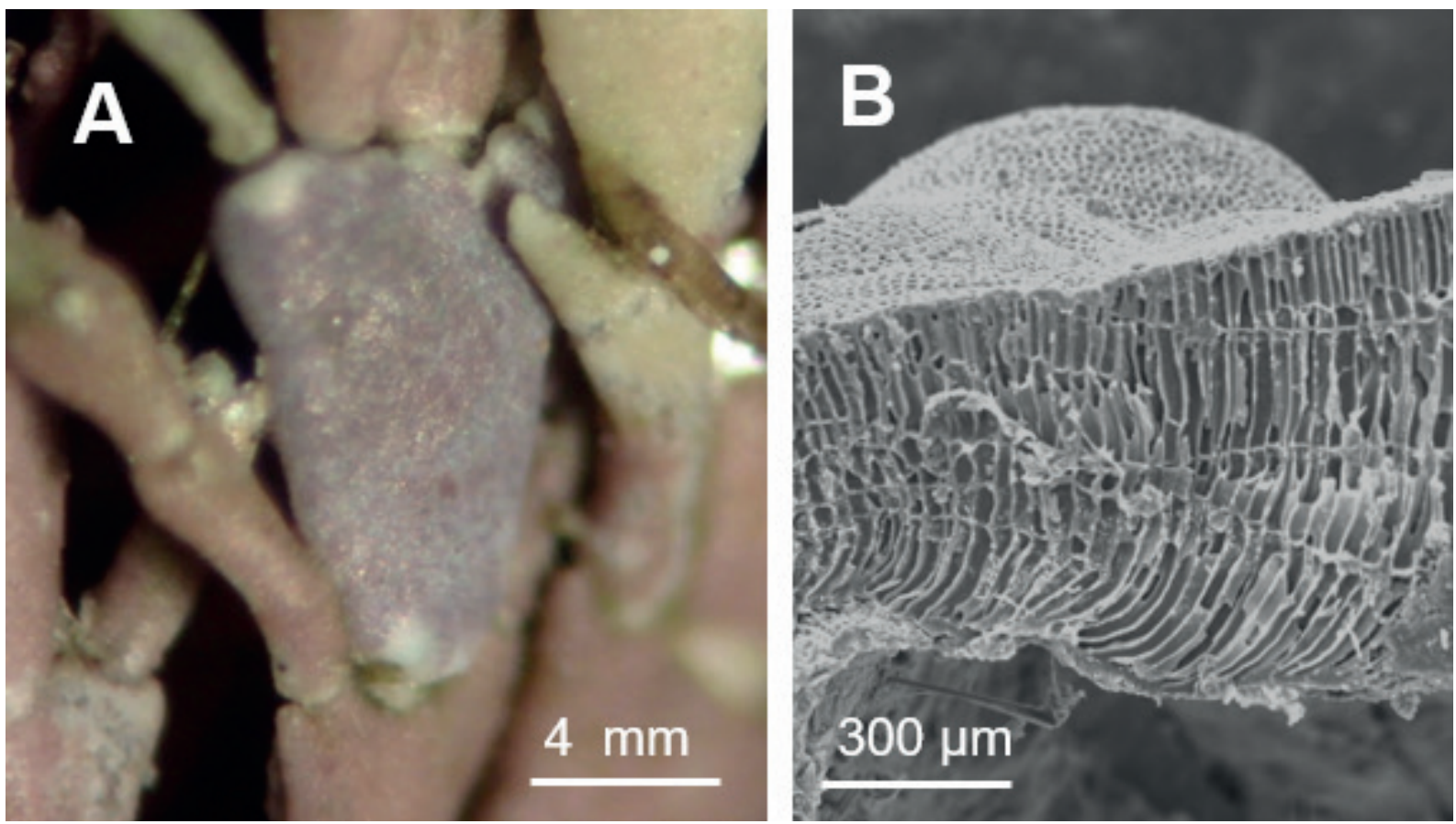

Figura 14. Titanoderma pustulatum var. confine. A. Epífito sobre Jania sp. con tonalidad púrpura. B. Talo dímero con varias capas de células corticales en empalizada, en sección transversal. (B) MEB.

Figure 14. Titanoderma pustulatum var. confine. A. Epiphytic on Jania sp. with purple colour. B. Cross-section showing dimerous thallus and layers of palisade cortical cells. (B) SEM.

pescar, A. García-Fernández \& I. Bárbara, SANT-Algae 33584. Ría de A Coruña, Islas de San Pedro, Al sur de Illa do Valdabal, 29TNJ444027, 21-VI-2016, intermareal inferior y submareal (3 m), epífita sobre $G$. baccata, A. García-Fernández \& I. Bárbara,
SANT-Algae 33585, 33587. Primera cita para Galicia. MINHO: Belinho, 29TNG162040, 09-X-2018, intermareal inferior rocoso, sobre Gigartina pistillata, J. Lugilde \& D. Borges, SANT-Algae 33622. Primera cita para Portugal. 


\section{TAXA EXCLUDENDAE}

Lithophyllum duckerae Woelkerling

Las citas de L. duckerae de Cornwall (IRvinE \& Chamberlain 1994) fueron confirmadas como L. hibernicum en HERNÁNDEZ-KANTÚN et al. (2015a), eliminando a $L$. duckerae de la flora de las Islas Británicas. El mismo protocolo se aplicó a las citas de Lugo y A Coruña de SAUvageau (1897) y LÁzARo-IBIzA (1889), descartándose esta especie del Atlántico ibérico. Lithophyllum duckerae está actualmente sinonimizada con $L$. racemus (Lamarck) Foslie, especie de distribución meridional (HERNÁNDEZ-KANTÚN et al. 2015a). En Hernández-Kantún et al. (2015a-b) se analizó la diversidad del género Lithophyllum demostrando que las citas de L. incrustans incluían diversidad críptica confirmándose otras dos especies en aguas europeas: $L$. hibernicum y L. bathyporum, además de $L$. incrustans. Estas tres especies están presentes en Galicia y el norte de Portugal, siendo de las especies de algas coralinas más abundantes: L. hibernicum en el intermareal y L. incrustans en el submareal, mientras que L. bathyporum es ocasional.

Phymatolithon purpureum (P.L. Crouan et H.M. Crouan) W.J. Woelkerling et L.M. Irvine. (Figura 15)

La presencia de Phymatolithon purpureum en Galicia y el Atlántico ibérico estaba sustentada por dos citas (Lugo y Pontevedra, BÁRBARA et al. 2003) y tres pliegos de herbario: SANT-Algae 13480, 13482 (Fig. 15) y 21656. El pliego SANT-Algae 13480 contenía dos ejemplares diferentes, que fueron renombradas como SANT-Algae 13480A y 13480B. SANT-Algae 13480A carece de conceptáculos de esporocistes enterrados en el talo, y del característico anillo de $P$. purpureum. Según diversos caracteres morfo-anatómicos citados en la literatura (WoELKERLING \& IRVINE 1986, IRVINE \& CHAMBERLAIN 1994) como: filamentos basales que ocupan hasta $50 \%$ del espesor del talo; de 1 a 4 capas de células epitalinas; conceptáculos de esporocistes (tetra/bisporocistes) viejos, enterrados varias capas bajo el talo. Los conceptáculos de esporocistes desarrollan también un anillo elevado y muy marcado, ancho $(<100 \mu \mathrm{m}$ de diámetro). Debido a la presencia de células iniciales subepitalinas de igual tamaño o mayores que las células corticales subyacentes, se ha identificado esta muestra como Mesophyllum expansum. Respecto a los pliegos SANT-Algae 13480B, 13482 y 21656 , presentan sinapsis secundarias entre células corticales de filamentos contiguos por lo que corresponden una especie del género Lithophyllum (provisionalmente Lithophyllum sp.). Existe otro pliego (SANT-Algae 13073) atribuido a esta especie, que tampoco corresponde a $P$. purpureum si no a Phyllariopsis purpurancens. Se trata de un error al ficharlo por presentar ambas especies similares códigos de introducción en el herbario. En conclusión, ninguno de los registros de $P$. purpureum en Galicia son asimilables a esta especie.

Recientemente, JEONG et al. (2019) propusieron que la especie de reciente descripción $P$. boreale sea considerada $P$. purpureum. Esta propuesta está basada en información molecular obtenida del material tipo de $P$. polymorphum f. papillatum (Foslie) Foslie, el cual se considera en la actualidad sinónimo de P. purpureum (Guiry \& Guiry 2020). Sin embargo, el lectotipo de $P$. purpureum no fue secuenciado y las localidades tipo de ambos táxones no son la misma (Mingant, Brest, Francia en P. purpureum; Helgoland, Alemania en $P$. polymorphum f. papillatum). A pesar de las similaridades morfo-anatómicas entre $P$. purpureum y $P$. boreale en cuanto a conceptáculos de esporocistes con anillo emergente y grueso y placas de poro cóncavas (e.g. Irvine \& Chamberlain 1994, Adey et al. 2018), consideramos que es necesario el estudio molecular del lectotipo de $P$. purpureum con el fin de confirmar que $P$. boreale y $P$. purpureum no son diferentes.

\section{AGRADECIMIENTOS}

El primer autor agradece a la fundación INDITEX-UDC la ayuda económica proporcionada para realizar una estancia de investigación en la Universidade de PortoCIIMAR (Portugal). Agradecimientos también a Verónica García-Redondo, Alicia 

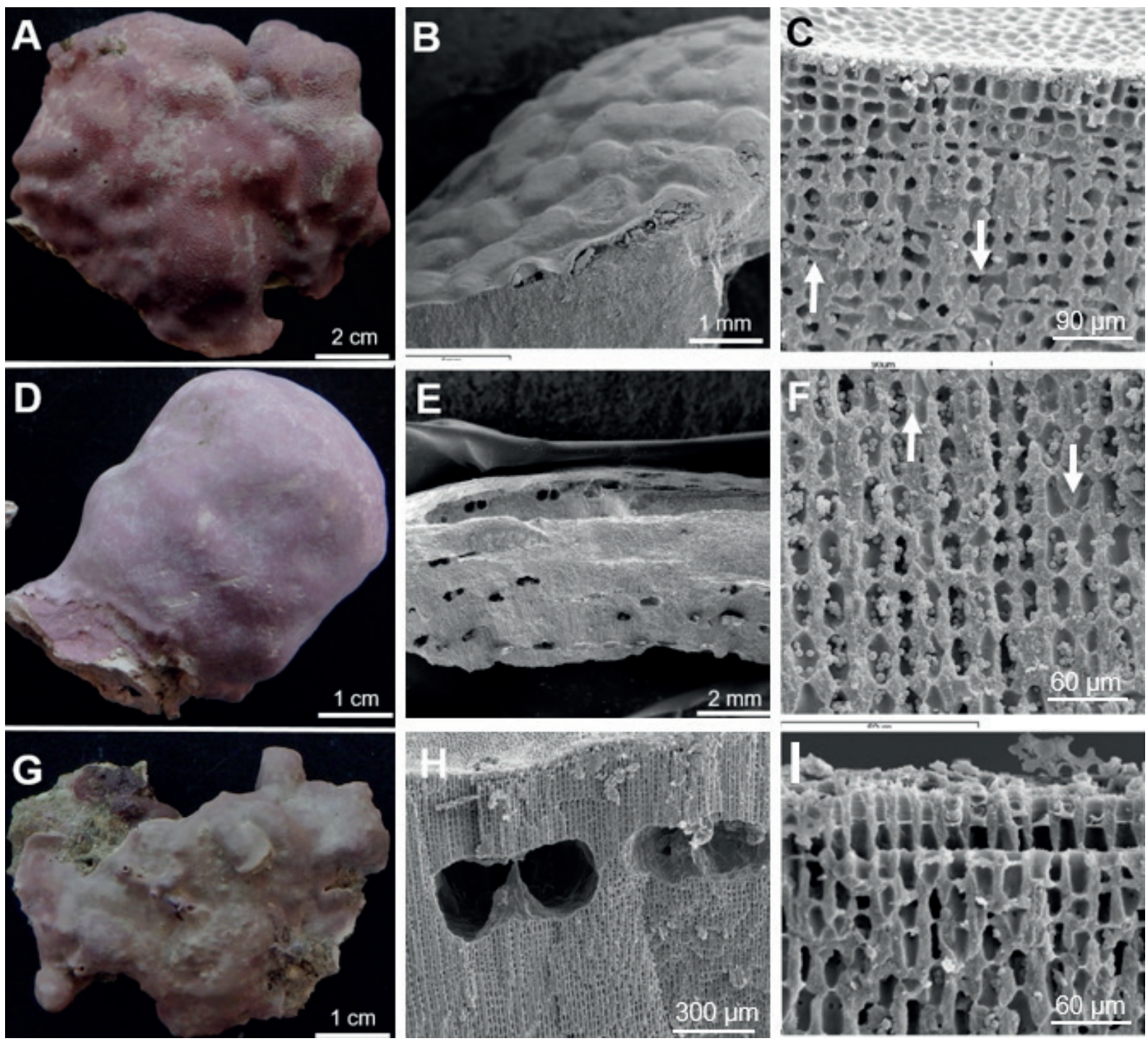

Figura 15. Material del Herbario SANT identificado previamente como Phymatolithon purpureum. SANT-Algae 13480A: Mesophyllum expansum. A. Vista superficial. B. Conceptáculos multiporados de tetrasporocistes en vista superficial. C. Células epitalinas redondeadas y células iniciales subepitalinas de mayor o igual tamaño que las células subyacentes. Celulas corticales de filamentos vegetativos contiguos conectadas por fusiones celulares. SANT-Algae 13480B: Lithophyllum sp. D. Vista superficial. E. Conceptáculos uniporados vacíos, enterrados varias capas en el talo. F. Células corticales de filamentos contiguos unidas por sinapsis secundarias. SANT-Algae 13482: Lithophyllum sp. G. Vista superficial. H. Conceptáculos uniporados vacíos con columela calcifidada. I. Células de filamentos corticales contiguos unidas por sinapsis secundarias. Varias capas de células epitalinas con morfología triangular. (B, C, E, F, H, I) MEB.

Figure 15. SANT Herbarium specimens previously identified as Phymatolithon purpureum SANT-Algae 13480A: A. Surface view. B. Tetrasporangial multiporate conceptacles in surface view. C. Epithallial cells rounded and subepithallial initial cells longer than or as long as cells subtending them (cross-section). Cortical cells of vegetative contiguous filaments joined by fusion cells. SANT-Algae 13480B: D. Surface view. E. Empty conceptacles, buried several layers down the thallus surface. F. Cortical cells of vegetative contiguous filaments joined by secondary pit-connections (cross-section). SANT-Algae 13482: G. Surface view. H. Uniporate conceptacles empty, with a calcified columella. I. Cortical cells of vegetative contiguous filaments joined by secondary pit-connections. Several layers of triangular epithallial cells (cross-section). (B, C, E, F, H, I) SEM.

García-Fernández, Catarina Torres y João Franco por la ayuda en la recolección de las muestras. De la misma manera, agradeci- mientos a David García San León (herbario SANT) y a Leonel Pereira (herbario COI) por su colaboración en la búsqueda de material de 
herbario. Losautores Marcos RubalyPuriVeiga agradecen la financiación parcial por el proyecto No. 029818, cofinanciado por COMPETE 2020, Portugal 2020 y la Unión Europea a través de ERDF, y por la FCT con fondos nacionales, y a través del proyecto UIDB/04423/2020 y UIDP/04423/2020.

\section{REFERENCIAS}

Adey, H.W. \& McKibisn, D.L. (1970). Studies on the maerl species Phymatolithon calcareum (Pallas) nov. comb. and Lithothamnium coralloides Crouan in the Ria de Vigo. Botanica Marina 13: 100-106.

Adey, H.W. Hernandez-Kantún, J.J., GABRIElson, W.P., Nash, C.M. \& HayeK C.L. (2018). Phymatolithon (Melobesioideae, Hapalidiales) in the Boreal-Subarctic transition zone of the North Atlantic: A correlation of plastid DNA markers with morpho-anatomy, ecology, and biogeography Smithsonian Contributions to the Marine Sciences 41(8): 90 pp.

Anglès d'Auriac, M., Le Gall, L., Peña, V., Hall-Spencer, J.M., Steneck, R.S., Fredriksen, S., Gitmark, J., Christie, H., Husa, V., Sofie Grefsrud, E. \& Rinde, E. (2019). Efficient coralline algal psbA mini barcoding and high-resolution melt (HRM) analysis using a simple custom DNA preparation. Scientific Reports 9: 578.

Araújo, R., Bárbara, I., Tibaldo, M., BereciBar, E., Díaz, P., Pereira, R., Santos, R. \& SousA-Pinto, I. (2009). Checklist of benthic marine algae and cyanobacteria of Northern Portugal. Botanica Marina 52: 24-46.

BAÑón R. (ED.) (2017) Inventario de la biodiversidadmarina de Galicia: Proyecto LEMGAL. Consellería do Mar, Xunta de Galicia, Santiago de Compostela. 570 pp.

Bárbara, I., Calvo, S., Cremades, J., Díaz, P., Veiga, J.J., Varela, L.C., Dosil, J., Peña, V. \& LóPEz-Rodríguez, M.C. (2003). Fragmenta Chorologica Occidentalia, Algae 7814-7892. Anales del Jardín Botánico de Madrid 55(2): 297-289.

Bárbara, I., Cremades, J., Calvo, S., López-RoDRÍGUEZ, M.C.\& DosiL, J. (2005a). Checklist of the benthic marine and brackish Galician algae. Anales del Jardín botánico de Madrid 62(1): 69-100.
Bárbara, I., Díaz, P., Araújo, R., Peña, V., Berecibar, E., Cremades, J., Freire, O., BaAmonde, S., Novo, T., Calvo, S., López-Rodríguez, M.C., Afonso-Carrillo, J., De Clerck, O., Santos, R., Sousa-Pinto, I., Tibaldo, M., Lagos, V., López, C., Secilla, A., Santolaria, A., Díez, I. \& Veiga, A.J. (2006). Adiciones corológicas y correciones a la flora bentónica marina del norte de la Península Ibérica. Nova Acta Científica Compostelana (Bioloxía) 15: 77-88.

Bárbara, I., Díaz, P., Cremades, J., Tibaldo, M., Freire, O., Peña, V., Lagos, V., Calvo, S., Veiga, A.J., Peteiro, C., López-Rodríguez, M.C.\& AraúJo, R. (2005b). Adiciones corológicas a la flora bentónica marina del norte de la Península Ibérica. Nova Acta Científica Compostelana (Bioloxía) 14: 83-88.

Bárbara, I., Díaz, P., Peña, V., Freire, O., BaAmonde, S., Cremades, J., Lagos, V. \& Lema, C. (2008). Adiciones corológicas a la flora bentónica marina de Galicia. Nova Acta Cientifica Compostelana (Bioloxía) 17: 169-175.

Bárbara, I., Díaz, P., Peteiro, C., Berecibar, E., Peña, V., Sánchez, N., Tavares, A.M., Santos, R., Secilla, A., Riera, F.P., Bermejo, R. \& GARCíA, V. (2012). Nuevas citas y aportaciones corológicas para la flora bentónica marina del Atlántico de la Península Ibérica. Acta Botánica Malacitana 37: 5-32.

Bárbara, I. García-Redondo, V. Díaz-Tapia, P. García-Fernández, A. Piñeiro-Corbeira, C. Peña, V. Lugilde, J. \& Cremades, J. (2019). Adiciones y correcciones a la flora bentónica marina del Atlántico ibérico norte. Acta Botanica Malacitana 44, 10 p.

Bárbara, I., Peña, V., García-Redondo, V., Díaz-Tapia, P., García-Fernández, A., Lugilde, J. \& Piñeiro-Corbeira, C. (2016). Nuevas citas y registros corológicos para la flora bentónica marina del noroeste ibérico. Acta Botanica Malacitana 41: 247-289.

BELTRÁn, M. \& BÁrbARA, I. (2003). Estudio morfológico comparado entre Corallina officinalis y C. elongata (Corallinales, Rhodophyta) en el noroeste de la Península Ibérica. Nova Acta Cientifica Compostelana (Bioloxía) 13: 5-16.

Bittner, L., Payri, C.E., Maneveltd, G.W., Couloux, A., Cruaud, C., De Reviers, B. \& 
LE GALL, L. (2011). Evolutionary history of the Corallinalles (Corallinophycidae, Rhodophyta) inferred from the nuclear, plastidial, and mitochondrial genomes. Molecular Phylogenetics and Evolution 61: 697-713.

Carro, B., López, L. Peña, V. Bárbara, I. \& BARREIRO, R. (2014). DNA barcoding allows the accurate assessment of European maerl diversity: a proof of concept study. Phytotaxa 190(1): 176-189.

Cremades, J., Bárbara, I. \& Veiga, A.J. (1997). Amphiroa vanbosseae (Corallinales, Rhodophyta) on European Atlantic coasts. Cryptogamie, Algologie 18(1): 11-17.

Gallardo, T., Bárbara, I., Afonso-Carrillo, J., Bermejo, R., Altamirano, M., Gómez Garreta, A., Barceló Martí, M.C., Rull Lluch, J., Ballesteros, E. \& De la Rosa, J. (2016). Nueva lista crítica de las algas bentónicas marinas de España. A new checklist of benthic marine algae of Spain. Algas. Boletín Informativo de la Sociedad Española de Ficología 51: 7-52.

Guiry, M.D. \& Guiry, G.M. (2020). AlgaeBase. World-wide electronic publication, National University of Ireland, Galway. http://www. algaebase.org. Consultado en: 28-XII-2020.

Hernández-Kantún, J.J., Rindi, F., Adey, W.H., Heesch, S., Peña, V., Le Gall, L. \& GABRIELSON, P.W. (2015a). Sequencing type material resolves the identity and distribution of the generitype Lithophyllum incrustans, and related European species L. hibernicum and L. bathyporum (Corallinales, Rhodophyta). Journal of Phycology 51: 791-807.

Hernández-Kantún, J.J., Riosmena-RodríGuez, R., Hall-Spencer, J.M., PeÑa, V., Maggs, C.A. \& Rindi, F. (2015b). Phylogenetic analysis of rhodolith formation in the Corallinales(Rhodophyta). European Journal of Phycology 50: 46-61.

Irvine, M.L. \& Chamberlain, M.Y. (1994). Seaweeds of the British Isles. Volume I. Rhodophyta. Part 2 B. Corallinales, Hildebrandiales. London: HMSO. 7: 276 pp.

Jeong, S.Y. Won, B.Y. Hassel, K. Cho, T.O. (2019). Revision of Phymatolithon purpureum (Hapalidiales, Rhodophyta) based on ultrastructural and molecular data. European Journal of Phycology 54(3):1-16.
LÁzARo-IBizA, D.B. (1889). Flora algológica del norte y noroeste de España. Anales de la Sociedad Española de Historia Natural 8: 275-294.

Le Gall, L.\& Saunders, G.W.(2007). A nuclear phylogeny of the Florideophyceae (Rhodophyta) inferred from combined EF2, small subunit and large subunit ribosomal DNA: establishing the new red algal subclass Corallinophycidae. Molecular Phylogenetics and Evolution 43: 1118-1130.

Lugilde YÁñez, J. (2020). Development of a Coralline Algae Flora (Corallinophycidae, Rhodophyta) in NW Iberia (Galicia and Northern Portugal). Thesis Doctoral, Universidad de A Coruña, 246 pp. http://hdl. handle.net/2183/26408

Lugilde, J., Bárbara, I. \& Peña, V. (2019). Variabilidad morfológica en Jania longifurca (Corallinales, Rhodophyta) en Galicia (noroeste de España) Anales del Jardín Botánico de Madrid 76(1): e079.

Lugilde, J., Peña, V. \& BÁrbara, I. (2016). El orden Corallinales sensu lato (Rhodophyta) en el Atlántico ibérico: estado actual de su conocimiento. Anales del Jardín Botánico de Madrid 73(2): e038 2016. ISSN: 0211-1322.

Lugilde, J., Peña, V. \& Bárbara, I. (2017). Morfología y distribución de Jania virgata (Corallinalles, Rhodophyta) en Galicia. Nova Acta Cientifica Compostelana (Bioloxía): 105-116. ISSN 2340-0021.

Pardo, C., López, L., Peña, V., HernándezKantún, J., Le Gall, L., Bárbara, I. \& BArreiro, R. (2014a). A multilocus species delimitation reveals a striking number of species of Coralline algae forming maerl in the OSPAR maritime area. Plos One 9: e1044073.

Pardo, C., Peña, V., Bárbara, I., Valero, M. \& BARreiro R. (2014b). Development and multiplexing of the first microsatellite markers in a coralline red algae (Phymatolithon calcareum, Rhodophyta). Phycologia 53(5): 474-479.

Pardo, C., Peña, V., Barreiro, R. \& Bárbara, I. (2011). A molecular revision of genus Corallina (Corallinales, Rhodophyta) in the Atlantic Iberian Peninsula. European Journal of Phycology 46(1): $182 \mathrm{pp}$. 
Pardo, C., Peña, V., Barreiro, R. \& Bárbara, I. (2015). A molecular and morphological study of Corallina s.l. (Corallinales, Rhodophyta) in the Atlantic Iberian Peninsula. Cryptogamie, Algologie 36(1): 31-54.

Peña, V. \& BÁRbara, I. (2004). Diferenciación morfológica y anatómica entre Lithothamnion corallioides y Phymatolithon calcareum (Corallinales, Rhodophyta) en dos bancos de maerl de la Ría de Arousa (N.O. Península Ibérica). Anales de Biología 26: 21-27.

Peña, V. \& BÁrbarA, I. (2006). Los fondos marinos de maerl del Parque Nacional de las Islas Atlánticas (Galicia, España): distribución, abundancia y flora asociada. Nova Acta Cientifica Compostelana 15: 7-25.

Peña, V. \& BÁrbara, I. (2008a). Biological importance of an Atlantic maerl bed of Benencia Island (Northwest Iberian Peninsula). Botanica Marina 51: 493-505.

Peña, V. \& BÁrbara, I. (2008b). Maerl community in the North-western Iberian Peninsula: a review of floristic studies and long-term changes. Aquatic Conservation of Marine. Freshwater Ecosystems 18: 339-366.

PeÑA, V. \& BÁrbara, I. (2009). Distribution of the Galician maerl beds and their shape classes (Atlantic Iberian Peninsula): proposal of Area in future conservation actions. Cahiers de Biologie Marine 50: 353-368.

Peña, V. Adey, H.W., Riosmena-Rodríguez, R., Moon-Yung, J., Afonso-CArrillo, J., HanGu, C. \& BÁrbara, I. (2011). Mesophyllum sphaericum sp. Nov. (Corallinales, Rhodophyta): A new maerl-forming species from the Northest atlantic. Phycological Society of America. Journal of Phycology 47: 911-927.

Peña, V., Hernández-Kantún, J.J., Grall, J., Pardo, C., López L., Bárbara, I., Le GALl, L., BARReiro, R. (2014). Detection of gametophytes in the maerl-forming species Phymatolithon calcareum (Melobesioideae,
Corallinales) assessed by DNA barcoding. Cryptogamie, Algologie 35(1): 15-25.

Peña, V., De Clerck, O., Afonso-Carrillo J., Ballesteros E., Bárbara I., Barreiro, R. \& LE GAll, L. (2015a). An integrative systematic approach to the genus Mesophyllum (Corallinales, Rhodophyta) in Atlantic and Mediterranean Europe. European Journal of Phycology 50(1): 20-36.

Peña, V., Pardo, C., López, L., Carro, B., Hernández-Kantún, J., Adey, H.W., Bárbara, I., Barreiro, R. \& Le Gall, L. (2015b). Phymatolithon lusitanicum sp. nov. (Hapalidiales, Rhodophyta): the third most abundant maerl-forming species in the Atlantic Iberian Peninsula. Cryptogamie, Algologie 36(4): 429-459.

Peña, V., Hernandez-Kantún, J.J., Adey, W.H. \& Le Gall, L. (2018). Assessment of coralline species diversity in the European coasts supported by sequencing of type material: the case study of Lithophyllum nitorum (Corallinales, Rhodophyta). Cryptogamie Algologie 39(1): 123-137.

PEZZOLESI, L., PEÑA, V., LE GALL, L., GABRIELSON, P.W., KALEB, S., HUGHEY, J.R., RODONDI, G., HERNANDEZ-KANTÚN, J.J., FELACE, A., BASSO, D., CERRANO, C. \& RINDI, F. (2019). Mediterranean Lithophyllum stictiforme (Corallinales, Rhodophyta) is a genetically diverse species complex: implications for species circumscription, biogeography and conservation of coralligenous habitats. Journal of Phycology 55(2): 473-492.

Sauvageau, C. (1897). Note préliminaire sur les algues marines du golfe de Gascogne. Journal de Botanique 11: 1-64.

Woelkerling, W.J. \& Irvine, L.M. (1986). The typification and status of Phymatolithon (Corallinaceae, Rhodophyta). British Phycological Journal 21: 55-80. 